\title{
BMJ Open Risk factors associated with paediatric unplanned hospital readmissions: a systematic review
}

\author{
Huaqiong Zhou, ${ }^{1,2}$ Pam A Roberts, ${ }^{2}$ Satvinder S Dhaliwal, ${ }^{3}$ Phillip R Della ${ }^{2}$
}

To cite: Zhou H, Roberts PA, Dhaliwal SS, et al. Risk factors associated with paediatric unplanned hospital readmissions: a systematic review. BMJ Open 2019;9:e020554. doi:10.1136/ bmjopen-2017-020554

- Prepublication history and additional material for this paper are available online. To view these files, please visit the journal online (http://dx.doi org/10.1136/bmjopen-2018020554).

Received 10 November 2017 Revised 21 September 2018 Accepted 23 October 2018

Check for updates

C Author(s) (or their employer(s)) 2019. Re-use permitted under CC BY-NC. No commercial re-use. See rights and permissions. Published by BMJ.

${ }^{1}$ General Surgical Ward, Princess Margret Hospital for Children, Perth, Western Australia,

Australia

${ }^{2}$ School of Nursing, Midwifery and Paramedicine, Curtin University, Perth, Western Australia, Australia

${ }^{3}$ School of Public Health, Curtin University, Perth, Western Australia, Australia

Correspondence to Professor Phillip R Della; P.Della@curtin.edu.au

\begin{abstract}
Objective To synthesise evidence on risk factors associated with paediatric unplanned hospital readmissions (UHRs).

Design Systematic review.

Data source CINAHL, EMBASE (Ovid) and MEDLINE from 2000 to 2017.

Eligibility criteria Studies published in English with fulltext access and focused on paediatric All-cause, Surgical procedure and General medical condition related UHRs were included.

Data extraction and synthesis Characteristics of the included studies, examined variables and the statistically significant risk factors were extracted. Two reviewers independently assessed study quality based on six domains of potential bias. Pooling of extracted risk factors was not permitted due to heterogeneity of the included studies. Data were synthesised using content analysis and presented in narrative form.
\end{abstract}

Results Thirty-six significant risk factors were extracted from the 44 included studies and presented under three health condition groupings. For All-cause UHRs, ethnicity, comorbidity and type of health insurance were the most frequently cited factors. For Surgical procedure related UHRs, specific surgical procedures, comorbidity, length of stay (LOS), age, the American Society of Anaesthesiologists class, postoperative complications, duration of procedure, type of health insurance and illness severity were cited more frequently. The four most cited risk factors associated with General medical condition related UHRs were comorbidity, age, health service usage prior to the index admission and LOS.

Conclusions This systematic review acknowledges the complexity of readmission risk prediction in paediatric populations. This review identified four risk factors across all three health condition groupings, namely comorbidity; public health insurance; longer LOS and patients $<12$ months or between 13-18 years. The identification of risk factors, however, depended on the variables examined by each of the included studies. Consideration should be taken into account when generalising reported risk factors to other institutions. This review highlights the need to develop a standardised set of measures to capture key hospital discharge variables that predict unplanned readmission among paediatric patients.

\section{INTRODUCTION}

Unplanned hospital readmission (UHR) rate has been recognised as a key performance indicator for measuring the quality of care in paediatric healthcare services. ${ }^{1}$ Hospital

\section{Strengths and limitations of this study}

This is the first systematic review of the literature from 2000 to 2017 on risk factors associated with paediatric unplanned hospital readmissions.

- The rigorous methodology applied to this systematic review used a comprehensive electronic databases search strategy, strict inclusion, exclusion and quality assessment criteria to synthesise characteristics of the included studies, examined variables and the statistically significant risk factors.

- Pooling of extracted significant risk factors was not possible because the included studies were not homogeneous due to the different diagnoses, examined variables and follow-up time frames to identify readmissions. Therefore, data extracted from the included studies were synthesised using content analysis and presented in narrative form.

readmission is defined as subsequent admissions within a specified period after the initial/index hospitalisation. ${ }^{2}{ }^{3}$ Paediatric UHRs rates range from $3.4 \%$ to $28.6 \%$ and cost healthcare systems such as UK, USA and Canada up to $\$ 1$ billion per annum. ${ }^{4-9}$

Identification of risk factors associated with UHRs is increasingly being examined as a strategy to assist in reducing these rates. A systematic review ${ }^{10}$ conducted in 2011, identified 26 risk predictive models from 30 examined studies focused on adult general medical condition related UHRs. Readmission length of time measures used ranged from 30 days to 12 months. Overall, the performance of the 26 models was poor. The most commonly identified risk factors were medical comorbidity and use of medical services before the index admission. In a 2016 systematic review, ${ }^{11}$ limited to 28-day or 30-day readmissions and focused on adult health conditions, a total of 60 studies and 73 risk predictive models with inconsistent performance was noted. The predictive models focusing on general medical conditions showed moderate discriminative ability. Risk factors cited most frequently for all UHRs were comorbidities, length of stay (LOS) 
and previous hospital admissions. For condition-specific readmissions, such as cardiovascular and general medical diseases laboratory tests and medication were more associated with readmissions. ${ }^{11}$

There is only one review ${ }^{12}$ within the paediatric literature examining UHRs. This review focused on asthma-related UHRs and included 29 studies. Five significant predictive factors, including age $<5$ years old or adolescent; being African American; public or no insurers; previous hospitalisations prior to the index admission; underlying chronic complex conditions were identified. To date, there is no published review paper on risk factors associated with UHRs for general paediatric patients. This paper aimed to systematically review the current literature on risk factors of paediatric All-cause, Surgical procedure and General medical condition related UHRs. The objectives were to assess characteristics of included studies and to synthesise the identified risk factors.

\section{METHODS}

A systematic review was performed and reported according to the 2009 PRISMA (Preferred Reporting Items for Systematic Reviews and Meta-Analysis) Statement. ${ }^{13}$

\section{Data sources and search strategy}

An electronic database search was carried out using the CINAHL, EMBASE(Ovid), MEDLINE to identify studies published from 2000 to 2017. The key search terms included ('Readmission' or rehospitali* or readmission* or readmit* or re-admission*) AND (child* or infant* or toddler* or bab* or newborn* or neonat* or school age* or preschool or paediatric* or pediatric* or kid* or boy* or girl*) OR (adolescen* or teen* or youth or juvenile* or young person* or young people*) (see online supplementary appendix for full search strategy).

\section{Inclusion/exclusion criteria}

Articles eligible for inclusion were those published in English with full-text access. The focus of the included studies was paediatric patients with UHRs. Eligible studies were published in peer-reviewed journals with details of study design clearly stated and reported statistical analysis procedure/s. Abstract only references were excluded. Studies that included patients discharged from rehabilitation health services but readmitted to acute hospitals were excluded from this systematic review as it only focused on hospital readmission following discharge from acute healthcare services. Newborn or preterm newborn studies related UHRs were excluded as the index admission was the birth hospitalisation. In addition, studies focused on mental health condition related UHRs were also excluded due to the specialised nature of the discipline.

\section{Study selection}

After the initial literature searches, two authors independently screened titles, abstracts and appraised full papers against the inclusion and exclusion criteria. The process of exclusion was relatively straightforward and only a handful of studies warranted discussion between authors, to reach consensus as to whether they met the inclusion criteria. Moreover, the reference list of all identified relevant records were searched for additional studies.

\section{Data extraction}

Data were extracted from the 44 included studies. The data extraction comprised study characteristics, examined variables and statistically significant risk factors. Study characteristics included study setting, population, data source, timing of data collection, sample size, study design, model utilisation outcome, readmission rate and statistical analysis test/s used to identify risk factors (table 1). All examined variables or confounding factors and the significant risk factors were extracted into table 2 and detailed information was included in the online supplementary table. Studies were grouped based on the health conditions in both tables. Disagreements between two reviewers about the extracted data were resolved through group discussion.

\section{Quality assessment}

Two independent reviewers completed the assessment of study quality. Six domains of potential bias ${ }^{14}$ were used to assess the 44 included primary research studies. The six domains are: 1. Study participation: 'Was source population clearly defined?' 2. Study attrition: 'Was completeness of follow-up described and adequate?' 3. Prognostic factor measurement: 'Did prognostic factors measure appropriately?' 4. Outcome measurement: 'Was outcome defined and measured appropriately?' 5. Confounding measurement and account: 'Was confounders defined and measured?' 6. Analysis: 'Was analysis described and appropriate?' The ratings of 'Yes', 'Partly', 'No' or 'Unsure' was given to each domain and then an overall risk of 'low' or 'high' was assigned to each study.

\section{Data synthesis}

Pooling of extracted significant risk factors was not possible because the included studies were not homogeneous due to the different diagnoses, examined variables and follow-up time frames to identify readmissions. Therefore, data extracted from the included studies were synthesised using content analysis and presented in narrative form. ${ }^{11}$

\section{Patient and public involvement}

Patients and or public were not involved in this systematic review.

\section{RESULTS}

The initial electronic database search produced 11859 records. After removal of 4145 duplicates, a total of 7714 records remained. Titles and abstracts were then appraised and 7579 records were excluded due to irrelevance. Of the remaining 135 relevant references, a further 

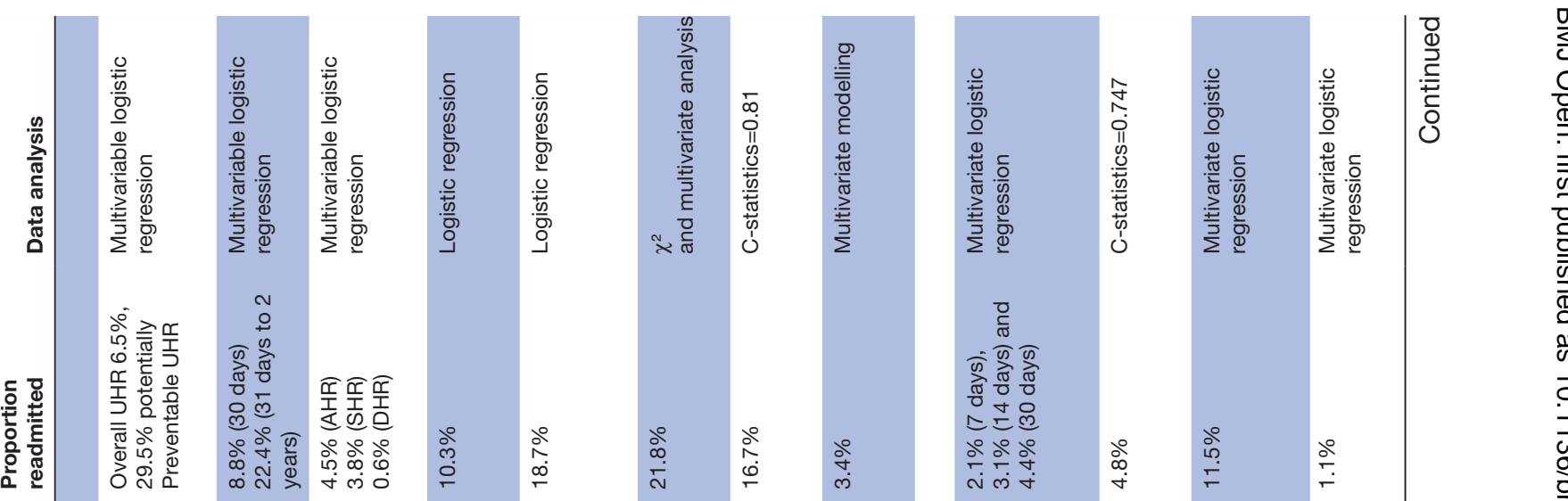

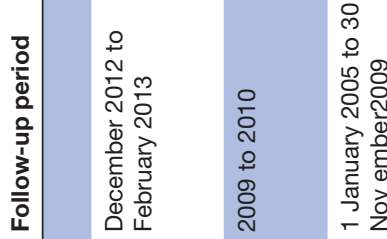

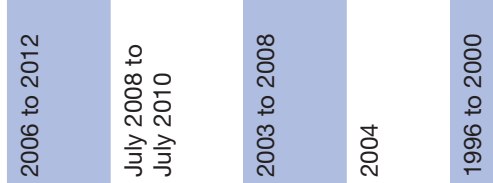

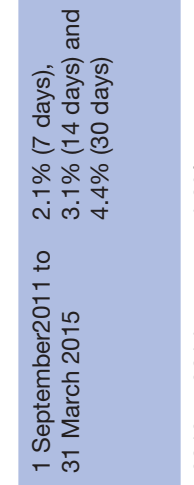

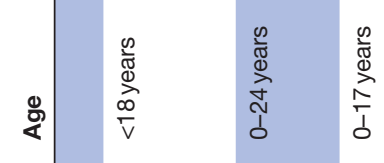
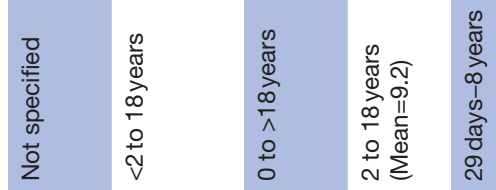

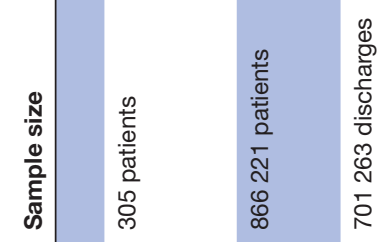
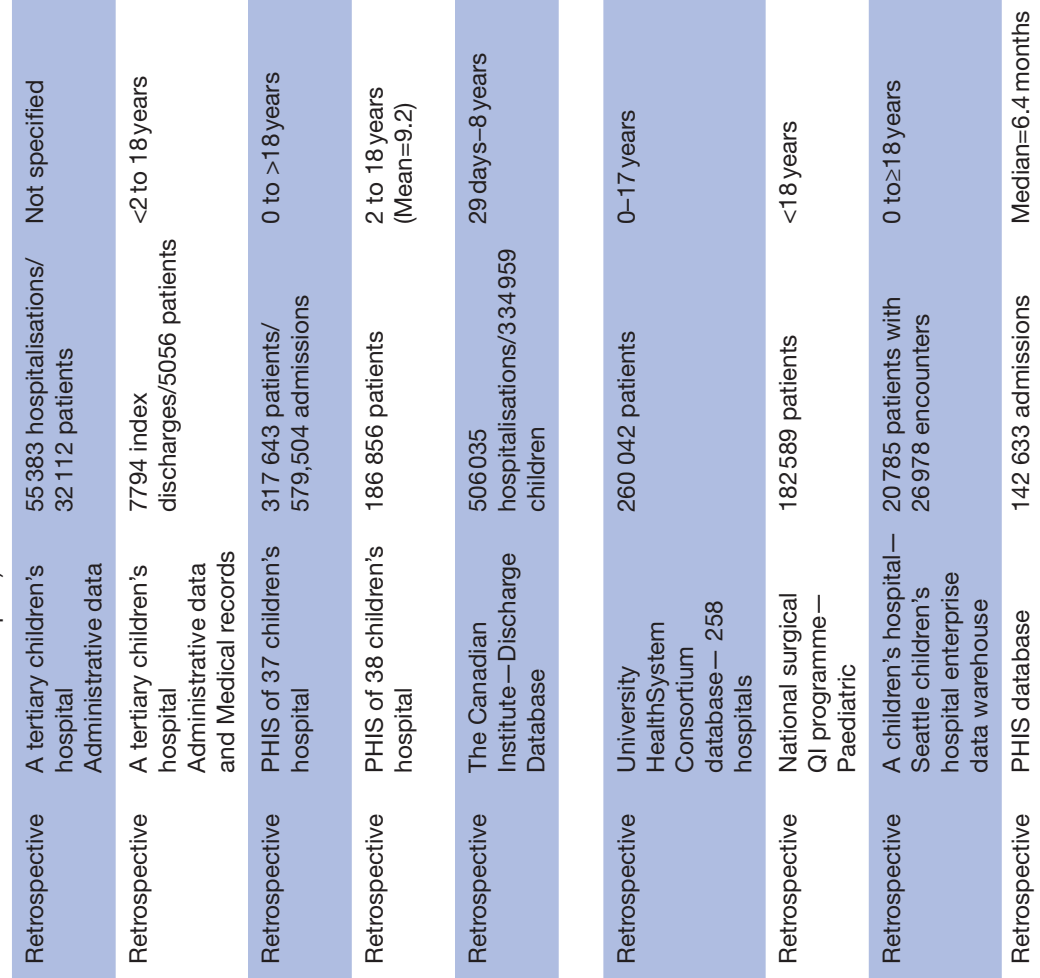

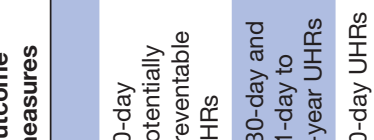
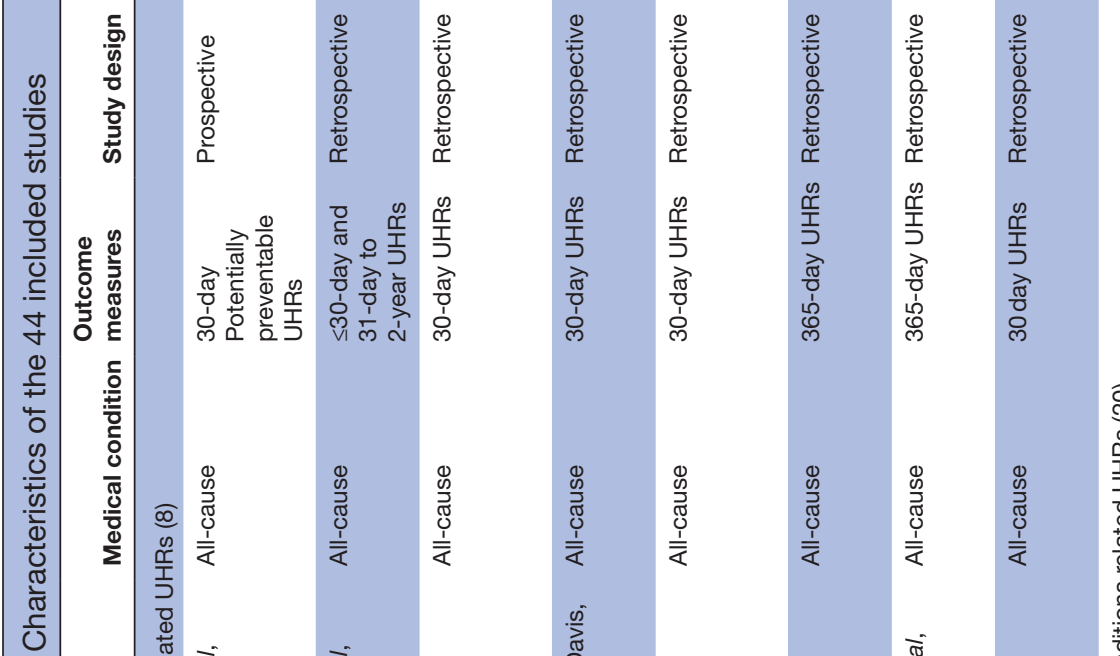

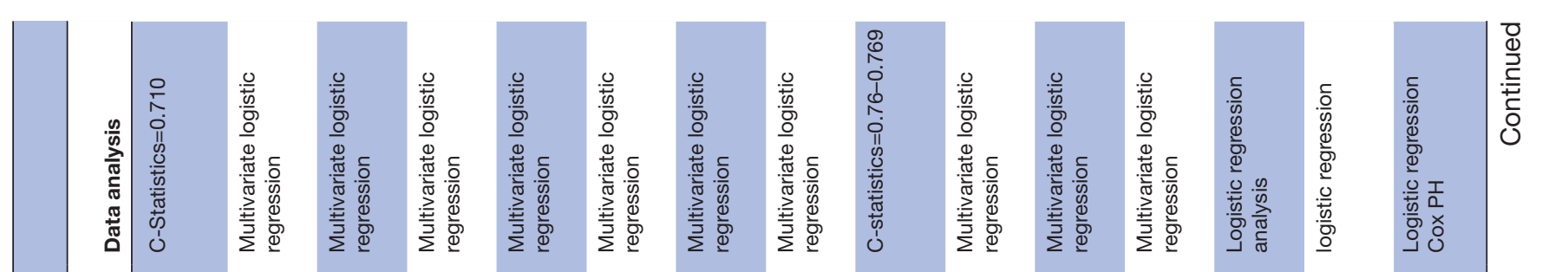

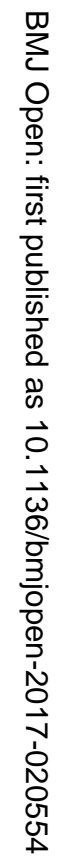

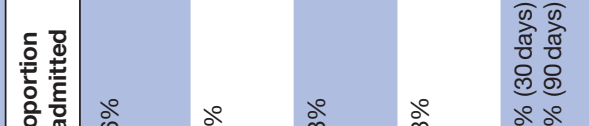

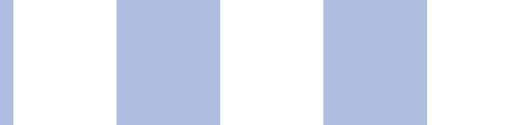

产兽

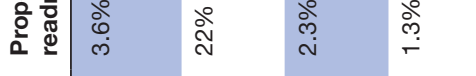

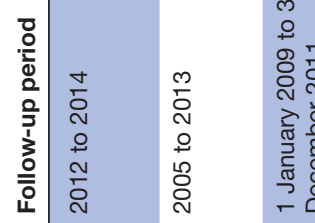

के ले 犬े

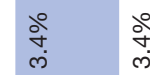

\section{象}

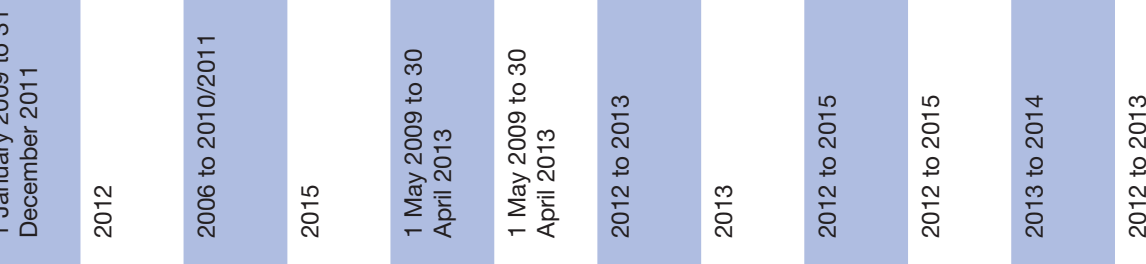

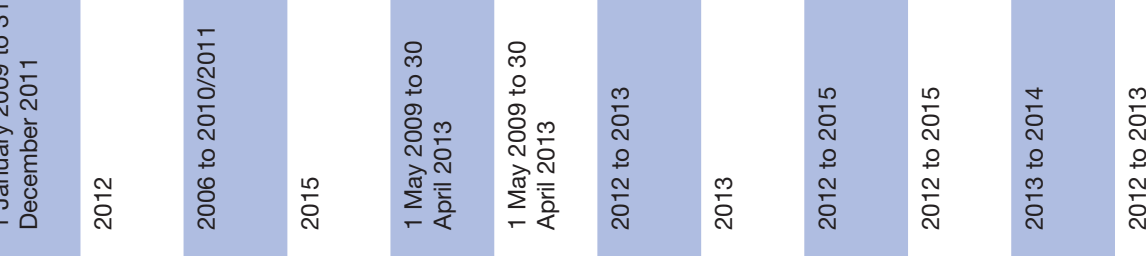

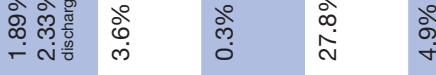

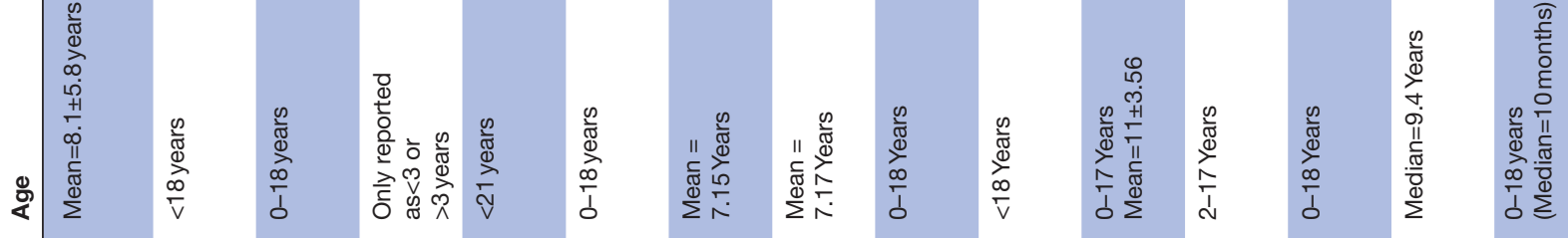

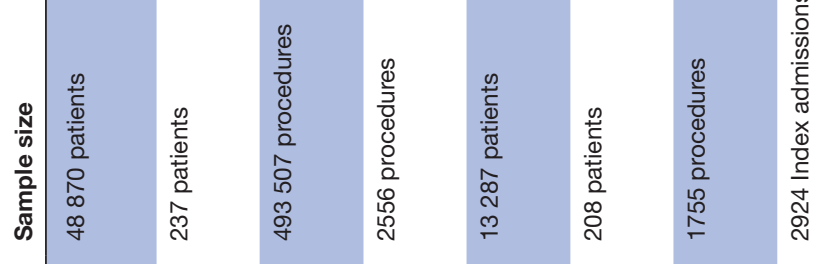
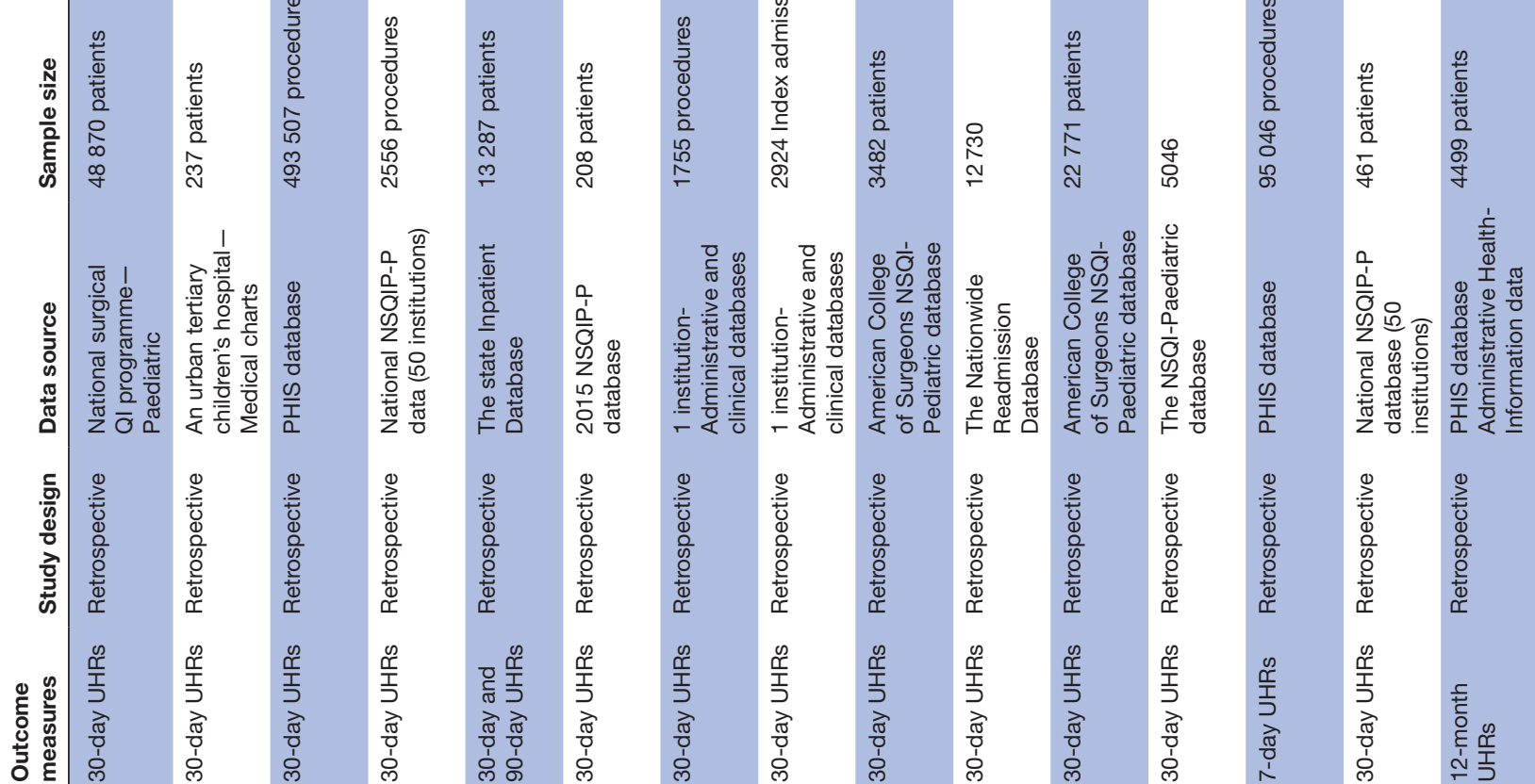

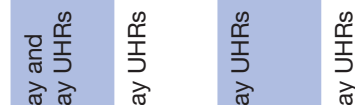

要 要 敢

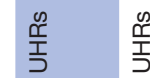

ธ음

लें⿰
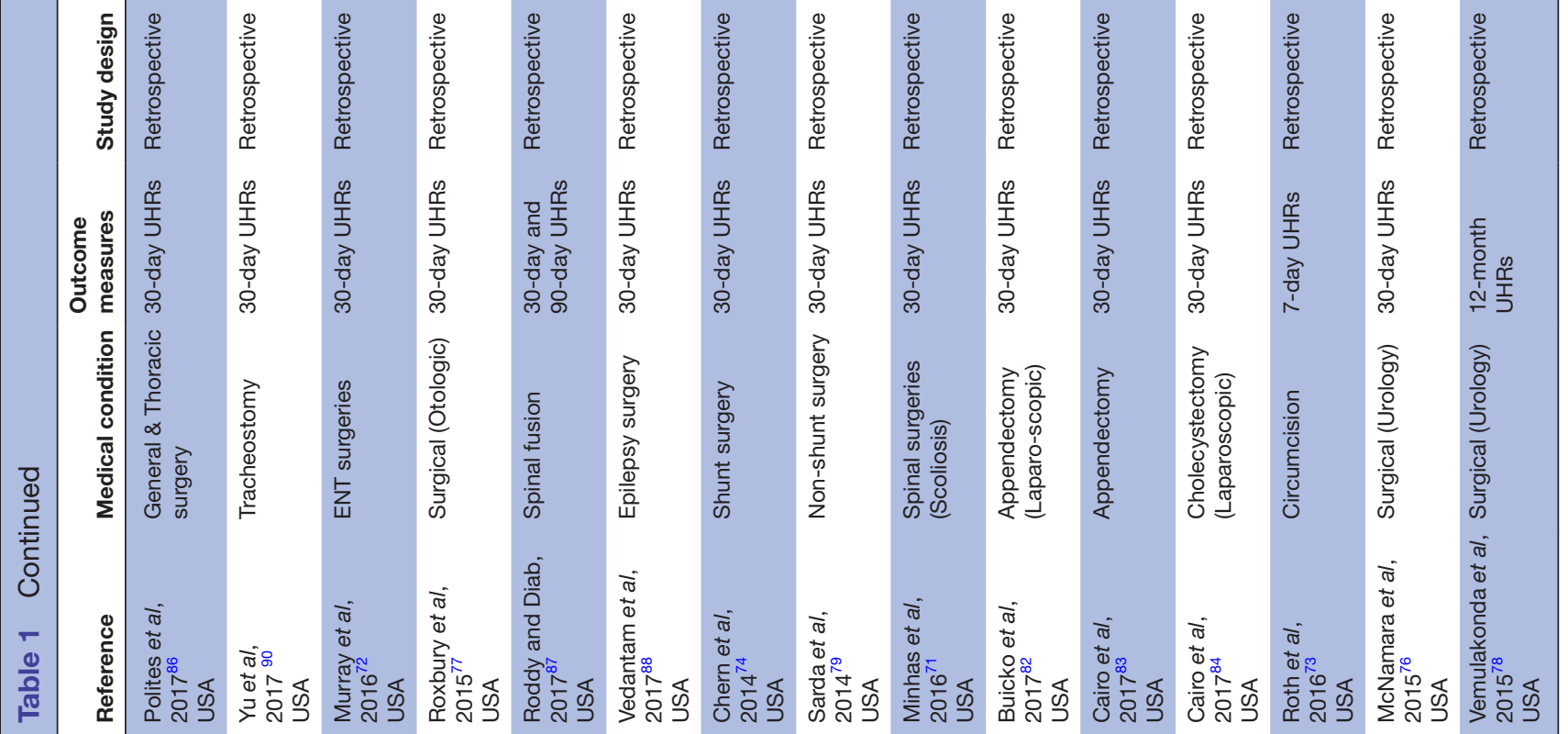

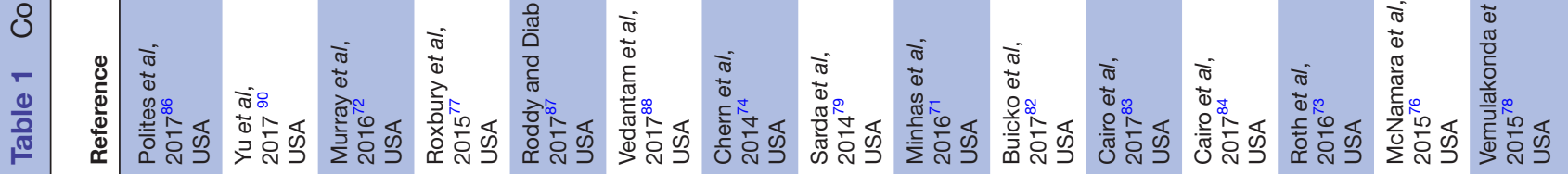




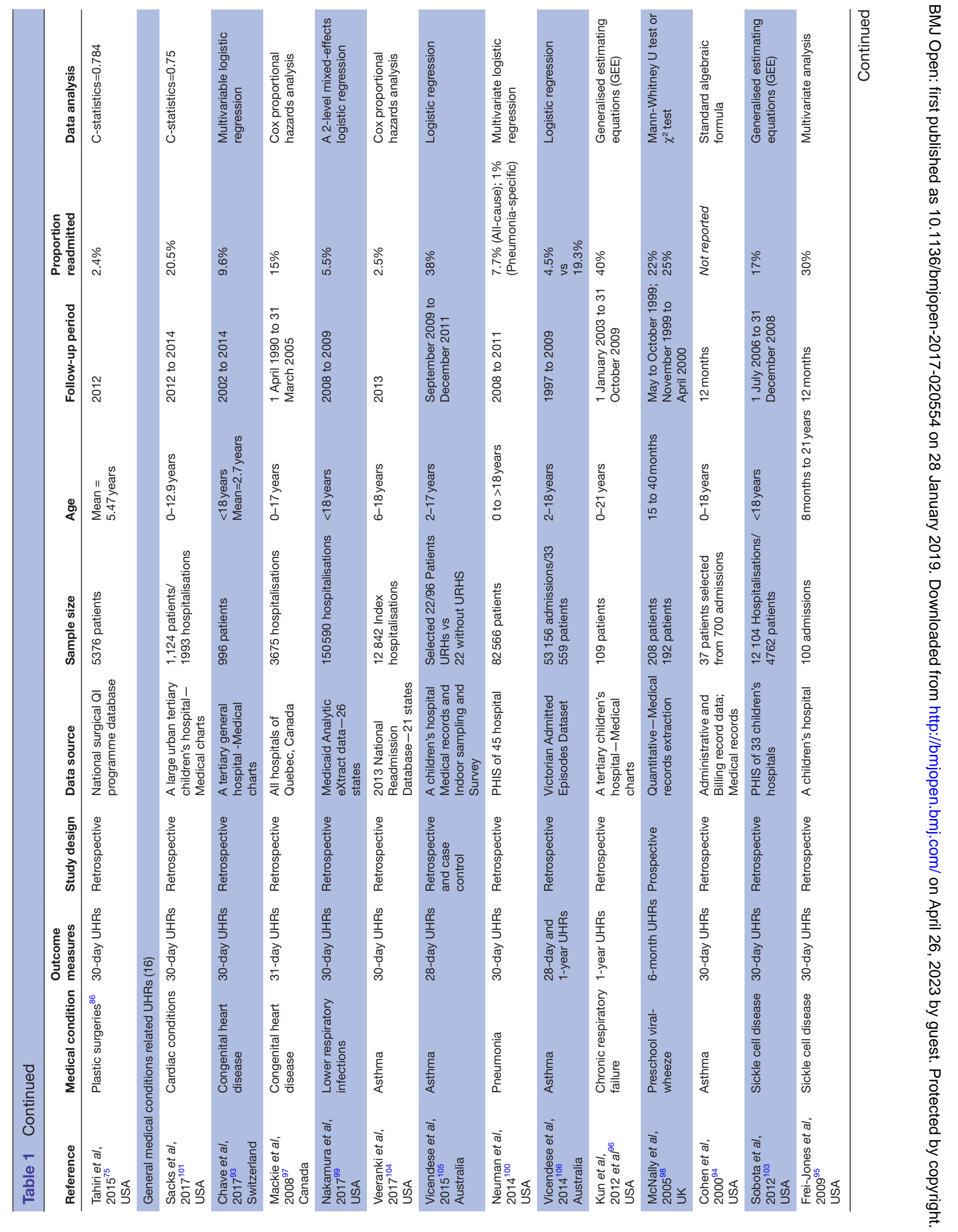


22 were excluded as they were conference abstracts only. A total of 113 references were reviewed as full-text and a further 75 were excluded against selection criteria. Four studies were excluded as they were published in Chinese, ${ }^{15}$ Korean, ${ }^{16}$ Portugese ${ }^{17}$ and Spanish. ${ }^{18}$ Studies that mixed paediatric and adult patients ${ }^{19-21}$ or mixed planned and unplanned readmissions ${ }^{22}$ or mixed Emergency Department presentations and hospital readmissions ${ }^{23-25}$ were excluded. Three studies ${ }^{26-28}$ that included patients initially discharged from rehabilitation health service but then admitted to an acute hospital were excluded. An integrative review ${ }^{12}$ on paediatric asthma related UHRs was excluded. As mentioned previously, studies ${ }^{29-53}$ examined newborn/preterm newborn-related UHRs and mental health condition related UHRs ${ }^{54-67}$ were excluded. A hand search reference list of the remaining 38 studies was conducted and six additional studies were identified. Finally, a total of 44 studies were included in this systematic review. Figure 1 is a flowchart as per PRISMA of the screening process of the database search results.

\section{Study quality appraisal}

The overall risk of bias of the 44 included studies was low when evaluated against the six domains of potential bias. The studies described the population of interest for key characteristics, the response rate information was clearly stated, an adequate proportion of the study population had complete data for all independent variables, the outcome variable readmission was measured with sufficient accuracy and the method of statistical analysis was appropriate for the design of the study. ${ }^{14}$

\section{Characteristics of the included studies}

Table 1 displays the characteristics of the final included studies of this systematic review. The 44 studies were conducted in several countries: USA $(n=36)$, UK $(n=3)$, Australia $(n=2)$, Canada $(n=2)$ and Switzerland $(n=1)$. Thirty of the included studies retrieved data from multiple sites and the other 14 accessed single healthcare service. A total of 33 included studies examined a combination of health database and medical records and the remaining 11 accessed database only. The included studies are grouped as per health conditions namely (1) All-cause related UHRs $(\mathrm{n}=8) ;^{4-8}$ 68-70 $^{2}$ (2) surgical procedure related UHRs $(\mathrm{n}=20),{ }^{71-90}$ including all surgical admissions $(n=3)$, cardiothoracic surgeries $(n=3)$, ear, nose and throat (ENT) surgeries $(n=2)$, neurosurgeries $(\mathrm{n}=5)$, abdominal surgeries $(\mathrm{n}=3)$, urological surgeries $(\mathrm{n}=3)$ and plastic surgeries $(\mathrm{n}=1)$ and (3) General medical condition related UHRs $(n=16)^{91-106}$ including cardiac conditions $(n=3)$, respiratory conditions $(n=8)$, blood disorders $(n=3)$, complex chronic conditions (CCC) $(n=1)$ and gastrointestinal conditions $(n=1)$.

All included studies used retrospective health data except Toomey $^{70}$ who employed a prospective research design including structured interview and reviewing medical records. Of the included studies, outcome measures of length of time from discharge to readmission 


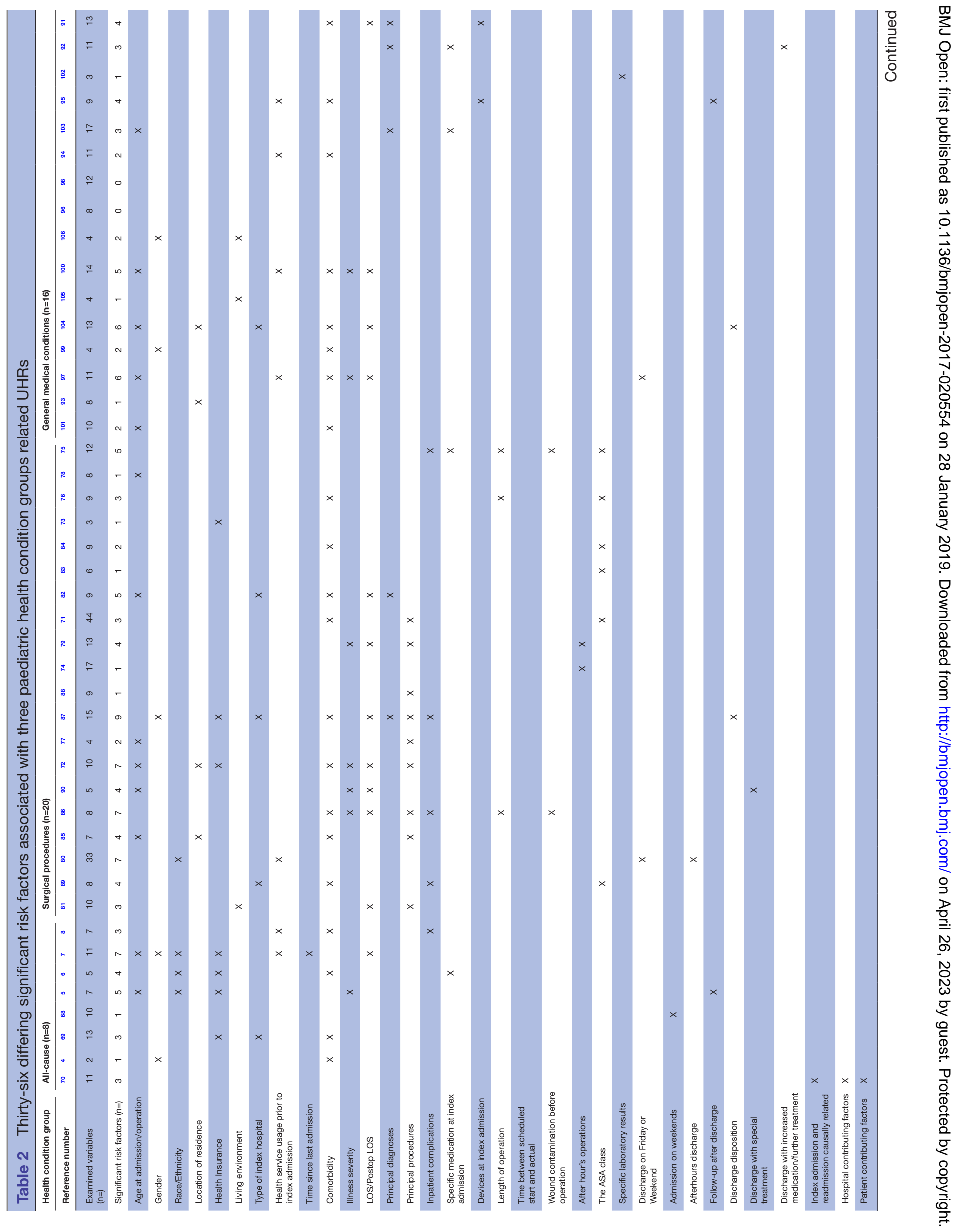




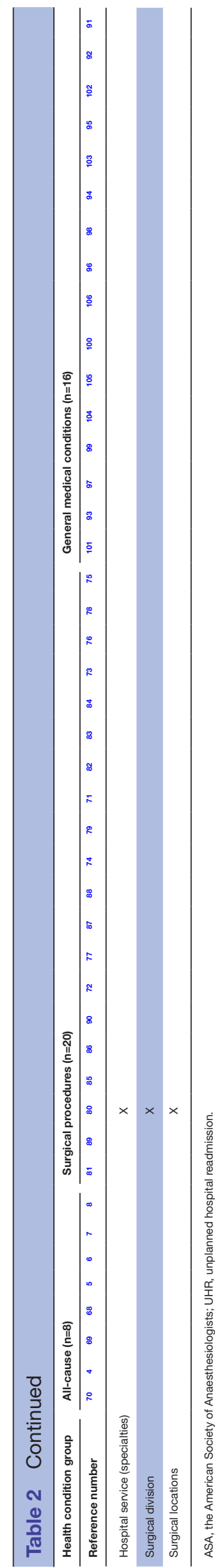

varied from 7 days for CCC, ${ }^{92}$ all surgical admissions, ${ }^{81}$ or circumcision ${ }^{73}$ to 1 year for All-cause, ${ }^{67}$ asthma ${ }^{106}$ and chronic respiratory failure ${ }^{96}$ related UHRs. Thirty-one of the 44 included studies adopted 28-day or 30-day UHRs measurement. The duration of time for the retrieved data used in the studies ranged from 3 months ${ }^{70}$ to 10 years ${ }^{78} .{ }^{106}$ The majority of included studies involved patients younger than 18 years. Five studies included patients older than 18 years with either blood disorder disease, ${ }^{102}$ CCC, ${ }^{4}$ gastric bleed, ${ }^{91}$ spinal fusion ${ }^{87}$ or all surgeries. ${ }^{80}$

Of included studies, the sample size was recorded in various units, such as Patients, Admissions, Index admissions, Hospitalisations, Index discharges, Discharges or Procedures. The sample size ranged from 100 admissions ${ }^{576395}$ to 866221 patients. ${ }^{4}$ UHR rates, if reported, varied from $<1 \%$ following postcircumcision ${ }^{73}$ to $40 \%$ in patients with chronic respiratory failure. ${ }^{96}$

All included studies employed logistic regression or equivalent to analyse the data. Most studies reported OR with $95 \% \mathrm{CI}$ and the result is considered as statistically significant when the $p$ value is less than 0.05 . Six included studies also reported risk predictive model performance. One model ${ }^{7}$ demonstrated high discriminative ability (C-statistic=0.81) for 12-month All-cause UHRs. The other models had moderate discrimination ability to predict 30 day UHRs following cardiac conditions, ${ }^{101}$ plastic, ${ }^{12}$ thoracic surgeries, ${ }^{86}$ scoliosis surgeries, ${ }^{13}$ or all surgical admissions $^{89}$ (C-statistic of $0.75,0.784,0.71,0.769$ and 0.74 , respectively).

\section{Examined variables/Confounding factors and Significant risk factors}

The variables or confounding factors examined varied across the 44 included studies. The number of examined variables of each included study ranging from 24 to $44 .^{71}$ Two of the included studies, after applying statistical analysis tests to the examined variables, yielded inconclusive findings ${ }^{9698}$ Thirty-six differing but significant risk factors were extracted and presented under the three health condition groupings (All-cause, Surgical procedure and General medical condition).

\section{Risk factors associated with All-cause UHRs}

The least number of studies $(\mathrm{n}=8)$ in the systematic review related to All-cause UHRs. Risk factors associated with All-cause UHRs and cited more frequently are comorbidity, ethnicity and health insurance. Patients' comorbidity was identified by four studies ${ }^{4869}$ with OR ranging from 1.2 to 5.61. Of these, chronic conditions $(n=3)$ was more frequently cited as a risk for readmission. Three studies cited race/ethnicity as a risk factor. Compared with other race/ethnicities, patients of Black race ${ }^{6}{ }^{7}$ or Asian $^{5}$ had $50 \%$ more likelihood of being readmitted. Patients from families with only public health insurance were identified at risk for readmission by three studies $(\mathrm{OR}=1.31$ to 1.48$) .{ }^{5-7}$ One study by Khan $2005,{ }^{69}$ however, identified patients with private health insurance were 1.14 


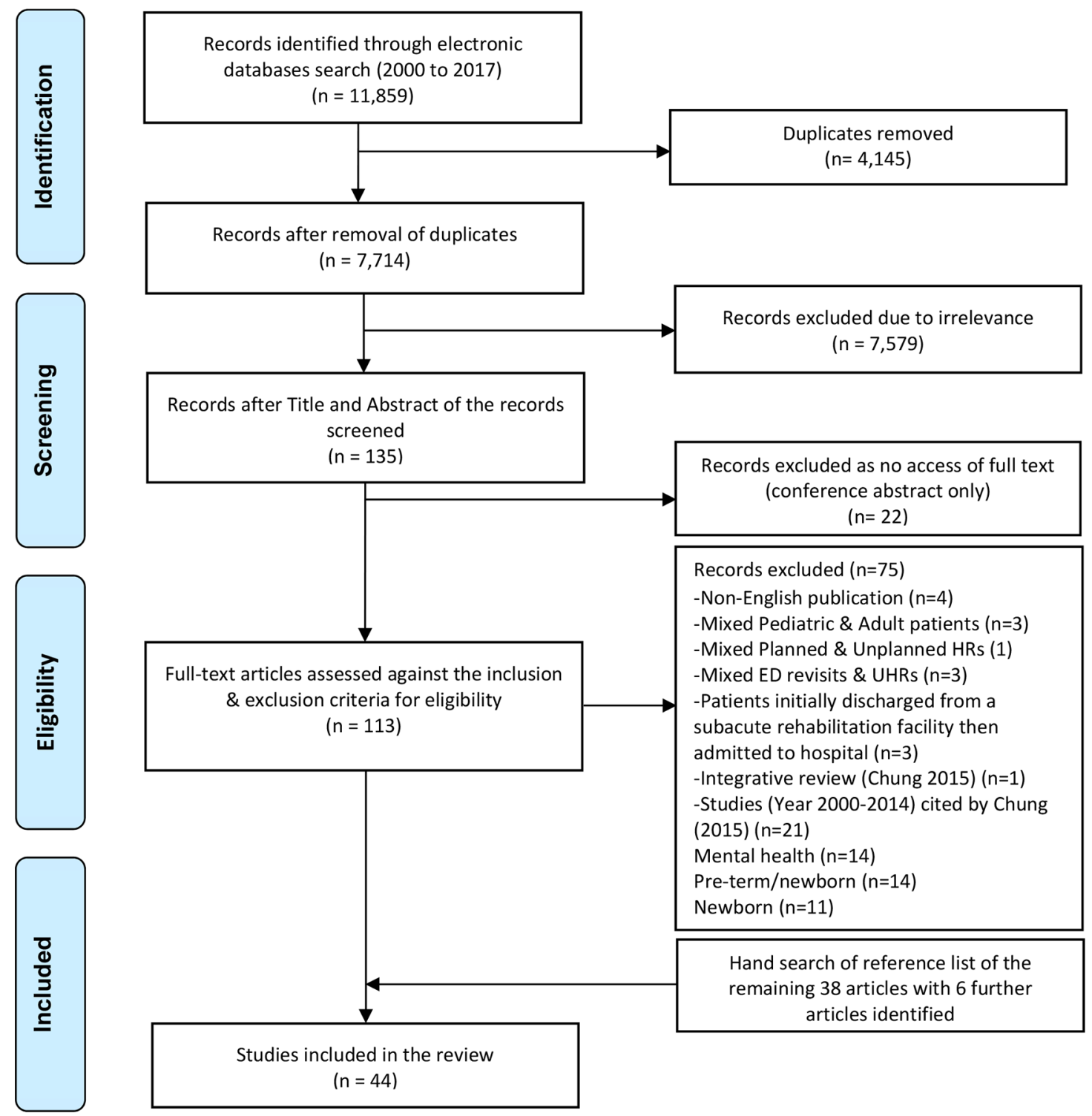

Figure 1 Flowchart for the search and study selection process (PRISMA).

times more likely to be readmitted to a different hospital. Other significant risk factors related to All-cause UHRs are displayed in table 2.

\section{Risk factors associated with surgical procedure related UHRs}

The greatest number of risk factors contributing to UHRs were found in the grouping of studies Surgical Procedure. Within the 20 included studies, the most frequently cited risk factors are comorbidity, specific surgeries, LOS, age, the American Society of Anaesthesiologists (ASA) class, development of complications during index admission, duration of surgery, type of health insurance and illness severity. Patients' comorbidity $7172768284-8789$ and specific surgical procedures ${ }^{71} 7277798185-88$ were each cited in nine differing studies. The type of comorbidities were not consistent among the studies ( $\mathrm{OR}=1.12$ to 10.08$)$.

In general, patients with longer LOS at index admission were found in seven studies to be at greater risk of readmission following surgical procedures $(\mathrm{OR}=1.01$ to 13.96) 727981828690 although one study ${ }^{87}$ found shorter than 3 days of hospitalisation at the index admission was a risk factor for patients who underwent spinal fusion $(\mathrm{OR}=1.89)$.

Age at index admission or surgery ${ }^{72} 7778828590$ and the ASA class ${ }^{71} 7580838489$ were cited in six differing studies. Age, however, was inconsistent across the studies. For example, patients either younger than 1 year $^{78}$ with urological surgeries or older than 13 years ${ }^{72}$ with ENT surgeries were more likely to be readmitted. The ASA class of 3 and above was associated with higher risk of UHRs $(\mathrm{OR}=1.78$ to 7.62$)$. In four studies, patients who developed medical or postoperative complications at the index admission were at risk of readmission with OR ranging from 1.34 to 11.92 . $^{75868789}$

Public insurance, ${ }^{72} 7387$ longer operating time, ${ }^{757686}$ and severe health conditions prior to surgeries ${ }^{72} 7966$ were all cited three times in different studies as increasing the risk of patients UHRs. Other significant risk factors related to surgical procedure related UHRs are displayed in table 2. 
Risk factors associated with general medical condition related UHRs

Sixteen studies were reviewed that examined General medical condition related UHRs. Four most frequently cited risk factors are comorbidity, age, health service usage prior to the index admission and LOS. A total of eight studies identified patients' comorbidity as a risk factor ( $\mathrm{OR}=1.1$ to 3.61$) .{ }^{91} 94959799-101104$ The most frequently cited comorbidity was chronic conditions $(n=5)$.

Age of patients at index admission was cited as a risk factor by five studies ${ }^{97100101103104}$ with OR ranging from 1.1 to 4.11. In particular, patients younger than 1 month ${ }^{100} 101$ or patients between 12 and 18 years ${ }^{100} 104$ were more likely to be readmitted. Three studies ${ }^{94} 95100$ reported patients with previous hospitalisation prior to the index admission were at higher risk of readmissions ( $\mathrm{OR}=4.7$ to 7.3). A further three studies ${ }^{91} 100104$ cited LOS as a risk factor with OR ranging from 1.13 to 1.56 . Patient stays $>4$ days for Asthma ${ }^{104}$ or $>7$ days for Pneumonia ${ }^{100}$ are more like to be readmitted. Other significant risk factors related to General medical condition related UHRs are displayed in table 2.

\section{DISCUSSION}

This systematic review identifies risk factors associated with paediatric UHRs. A total of 44 studies were reviewed and 36 differing significant risk factors were extracted. There are only four consistently cited paediatric readmission risk factors across all included studies, namely comorbidity, public health insurance, longer LOS at the index admission and patients either younger than 12 months or those 13-18 years of age. The results demonstrate a shift in focus from All-cause UHRs to condition specific related UHRs, especially those involving surgical procedures. Overall, the 36 significant risk factors varied among studies focused on condition-specific related readmissions and some risk factors were not reported consistently across studies.

This systematic review has certain limitations. The database search was restricted to English publication only and full-text access was also required to allow comprehensive data extraction. Meta-analysis was not performed on the extracted significant risk factors as the included studies were not homogeneous due to the different diagnoses, examined variables and follow-up time frames to identify readmissions. This systematic review did not establish a definite cut-off age during the literature search although $0-18$ years is a widely accepted definition for paediatric patients. Consequently, five included studies had patients in their late teens or young adulthood (19-24 years). ${ }^{408791102}$ The inclusion of late adolescent and young adult under paediatric health services care is consistent with the finding of delayed transitions from paediatric to adult healthcare services. ${ }^{107}$ This systematic review did not restrict the follow-up time frame used by studies to identify UHRs, which resulted in data collection spanning 7 days to 21 years. This in turn contributed to a vast range of paediatric UHRs rates of $<1 \%$ to $>40 \%$. Nineteen included studies in this review investigated 28-day, 30-day or 31-day paediatric UHR rates, ranging from $1.3 \%$ to $38 \% .^{72}$ 92 The number of predictive models with performance reported for paediatric UHRs $(n=6)$ is very limited compared with the adult population $(\mathrm{n}=94) .{ }^{10}{ }^{11}$ This systematic review did not identify any paediatric based studies examining potentially preventable UHRs reported risk prediction model performance. In comparison, there are two developed models ${ }^{108} 109$ with high discriminative ability for adult patients.

\section{CONCLUSION}

This systematic review acknowledges the complexity of UHRs risk prediction in paediatric populations. The evidence on the utility of developed predictive models for paediatric UHRs, comparison to adult population literature, is very limited as no existing models have been validated externally. This review identified four consistently cited risk factors associated with paediatric UHRs. These include comorbidity, public health insurance, longer LOS at the index admission and patients either younger than 12 months or 13-18 years old. The identified risk factors depended on what variables were examined in each of the included studies. Therefore, consideration should be taken into account when generalising reported significant risk factors to other institutions.

This review concludes that a focus on the development of potentially preventable/avoidable UHRs risk predictive models for paediatric patients is required as some unplanned readmissions might be unavoidable due to medical complexity. ${ }^{110}$ Future studies should use a combined approach of administrative and clinical medical data. Also, there is a need to examine if paediatric potentially/avoidable UHRs are associated with patients' social complexity (ie, language proficiency) and comprehensiveness of discharge information (written and verbal communication).

The utmost priority is to develop a standardised set of measures to capture key hospital discharge variables that predict unplanned readmission among paediatric patients. Key challenges include time frame used to measure readmissions, unit of measure on which to record/calculate readmission and variables to be examined. Establishing the most appropriate length of time (being discharge to readmission) to measure UHRs is the first challenge. The second is to standardise the unit of measure that should be used to calculate the readmission rate, while the final challenge is to determine what variables should be extracted and examined to identify risk factors associated with UHRs. Once these challenges have been addressed, a parsimonious predictive model, with high sensitivity and specificity, can be developed for use in all healthcare settings, to identify and implement quality improvement plans for patients with high risk of UHRs. 
Acknowledgements We would like to acknowledge Ms Marta Rossignoli, Previous Librarian of Child and Adolescent Health Service, WA, for her assistance in the literature search.

Contributors $\mathrm{HZ}$ conceptualised and designed the systematic review, participated in literature search, paper selection, critical appraisal and data analyses, drafted the initial manuscript and approved the final manuscript as submitted. PAR contributed in the paper selection and data extraction, critical appraisal and initial analyses, critically reviewed the manuscript and approved the final manuscript as submitted. SSD contributed in the paper selection and data extraction, critical appraisal and initial analyses, critically reviewed the manuscript and approved the final manuscript as submitted. PRD conceptualised and designed the systematic review, participated in the paper selection, data extraction, critical appraisal and data analyses, critically reviewed the manuscript and approved the final manuscript as submitted. All authors approved the final manuscript as submitted and agree to be accountable for all aspects of the work.

Funding All phases of this study were supported by a grant from the Australian Research Council-ARC Linkage Grant (Project ID: LP140100563). HZ is also supported by the Academic Support Grant 2016 \& the Academic Research Grant 2014 from the Nursing and Midwifery office, Western Australian Department of Health.

Competing interests None declared.

Patient consent for publication Not required.

Provenance and peer review Not commissioned; externally peer reviewed.

Data sharing statement № additional data are available.

Open access This is an open access article distributed in accordance with the Creative Commons Attribution Non Commercial (CC BY-NC 4.0) license, which permits others to distribute, remix, adapt, build upon this work non-commercially, and license their derivative works on different terms, provided the original work is properly cited, appropriate credit is given, any changes made indicated, and the use is non-commercial. See: http://creativecommons.org/licenses/by-nc/4.0/.

\section{REFERENCES}

1. Bardach NS, Vittinghoff E, Asteria-Peñaloza R, et al. Measuring hospital quality using pediatric readmission and revisit rates. Pediatrics 2013;132:429-36.

2. Australian Institute of Health and Welfare. National healthcare agreement: PI23-Unplanned hospital readmission rates. Secondary National healthcare agreement: PI23-Unplanned hospital readmission rates. 2013 http://meteor.aihw.gov.au/content/index. phtml/itemld/497129

3. Department of Health and Human Services. Readmissions t hospital: percentage of unplanned readmissions within 28 days of separation, during the 6 month time period. Secondary Readmissions thospital: percentage of unplanned readmissions within 28 days of separation, during the 6 month time period. US: Department of Health and Human Services, 2012.

4. Wijlaars LP, Hardelid P, Woodman J, et al. Who comes back with what: a retrospective database study on reasons for emergency readmission to hospital in children and young people in England. Arch Dis Child 2016;101:714-8.

5. Coller RJ, Klitzner TS, Lerner CF, et al. Predictors of 30-day readmission and association with primary care follow-up plans. $J$ Pediatr 2013;163:1027-33.

6. Berry JG, Hall DE, Kuo DZ, et al. Hospital utilization and characteristics of patients experiencing recurrent readmissions within children's hospitals. JAMA 2011;305:682-90.

7. Feudtner C, Levin JE, Srivastava R, et al. How well can hospital readmission be predicted in a cohort of hospitalized children? A retrospective, multicenter study. Pediatrics 2009;123:286-93.

8. Beck CE, Khambalia A, Parkin PC, et al. Day of discharge and hospital readmission rates within 30 days in children: a populationbased study. Paediatr Child Health 2006;11:409-12.

9. Berry JG, Toomey SL, Zaslavsky AM, et al. Pediatric readmission prevalence and variability across hospitals. JAMA 2013;309:372-80.

10. Kansagara D, Englander $\mathrm{H}$, Salanitro A, et al. Risk prediction models for hospital readmission: a systematic review. JAMA 2011;306:1688-98.

11. Zhou H, Della PR, Roberts $P$, et al. Utility of models to predict 28-day or 30-day unplanned hospital readmissions: an updated systematic review. BMJ Open 2016;6:e011060.
12. Chung HS, Hathaway DK, Lew DB. Risk factors associated with hospital readmission in pediatric asthma. $J$ Pediatr Nurs 2015;30:364-84.

13. Shamseer L, Moher D, Clarke M, et al. Preferred reporting items for systematic review and meta-analysis protocols (PRISMA-P) 2015: elaboration and explanation. BMJ 2015;349:g7647.

14. Hayden JA, Côté P, Bombardier C. Evaluation of the quality of prognosis studies in systematic reviews. Ann Intern Med 2006;144:427-37.

15. You JY, Shu C, Gong CH, et al. [Readmission of children with bronchopulmonary dysplasia in the first 2 years of life: a clinical analysis of 121 cases]. Zhongquo Dang Dai Er Ke Za Zhi 2017; $19: 1056-60$

16. Hong YC, Choi EJ, Park S-A. Risk Factors of readmission to hospital for pneumonia in children. Pediatric Infection and Vaccine 2017;24:146-51.

17. Mendes P, Fonseca M, Aguiar I, et al. [Readmission to an adolescent psychiatry inpatient unit: readmission rates and risk factors]. Acta Med Port 2017;30:769-74.

18. Diz-Lois Palomares MT, de la Iglesia Martínez F, Nicolás Miguel $\mathrm{R}$, et al. [Predictive factors of unplanned hospital readmission in patients discharged at a short stay medical unit]. An Med Interna 2002;19:221-5.

19. Buyantseva LV, Brooks J, Rossi M, et al. Risk factors associated with 30-day asthma readmissions. J Asthma 2016;53:684-90.

20. Frolkis A, Kaplan GG, Patel AB, et al. Postoperative complications and emergent readmission in children and adults with inflammatory bowel disease who undergo intestinal resection: a populationbased study. Inflamm Bowel Dis 2014;20:1316-23.

21. Schwam ZG, Michaelides E, Schwam JR, et al. Comparing 30-day morbidity and mortality in pediatric and adult otologic surgery. Otolaryngol Head Neck Surg 2017;157:830-6.

22. Wrubel DM, Riemenschneider KJ, Braender $\mathrm{C}$, et al. Return to system within 30 days of pediatric neurosurgery. $J$ Neurosurg Pediatr 2014;13:216-21.

23. Hudson SM. Hospital readmissions and repeat emergency department visits among children with medical complexity: an integrative review. J Pediatr Nurs 2013;28:316-39.

24. Hudson SM, Mueller M, Hester WH, et al. At-risk characteristics for hospital admissions and ED visits. J Spec Pediatr Nurs 2014:19:183-93.

25. Basques BA, Lukasiewicz AM, Samuel AM, et al. Which pediatric orthopaedic procedures have the greatest risk of adverse outcomes? J Pediatr Orthop 2017;37:429-34.

26. Cushman DG, Dumas HM, Haley SM, et al. Re-admissions to inpatient paediatric pulmonary rehabilitation. Pediatr Rehabil 2002;5:133-9.

27. Jurgens V, Spaeder MC, Pavuluri P, et al. Hospital readmission in children with complex chronic conditions discharged from subacute care. Hosp Pediatr 2014;4:153-8.

28. O'Brien JE, Dumas HM, Nash CM, et al. Unplanned readmissions to acute care from a pediatric postacute care hospital: incidence, clinical reasons, and predictive factors. Hosp Pediatr 2015;5:134-40.

29. Mourani PM, Kinsella JP, Clermont G, et al. Intensive care unit readmission during childhood after preterm birth with respiratory failure. J Pediatr 2014;164:749-55.

30. Smith VC, Zupancic JA, McCormick MC, et al. Rehospitalization in the first year of life among infants with bronchopulmonary dysplasia. J Pediatr 2004;144:799-803.

31. Goyal N, Zubizarreta JR, Small DS, et al. Length of stay and readmission among late preterm infants: an instrumental variable approach. Hosp Pediatr 2013:3:7-15.

32. Torigoe K, Sasaki S, Hoshina J, et al. Predicting factors of plural hospitalization with pneumonia in low-birthweight infants. Pediatr Int 2011;53:446-53.

33. Tseng $\mathrm{YH}$, Chen $\mathrm{CW}$, Huang $\mathrm{HL}$, et al. Incidence of and predictors for short-term readmission among preterm low-birthweight infants. Pediatr Int 2010;52:711-7.

34. Morris BH, Gard CC, Kennedy K. Rehospitalization of extremely low birth weight (ELBW) infants: are there racial/ethnic disparities? J Perinatol 2005;25:656-63.

35. Chien YH, Tsao PN, Chou HC, et al. Rehospitalization of extremelylow-birth-weight infants in first 2 years of life. Early Hum Dev 2002;66:33-40.

36. Liese JG, Grill E, Fischer B, et al. Incidence and risk factors of respiratory syncytial virus-related hospitalizations in premature infants in Germany. Eur J Pediatr 2003;162:230-6.

37. Carbonell-Estrany X, Quero J, Bustos G, et al. Rehospitalization because of respiratory syncytial virus infection in premature infants younger than 33 weeks of gestation: a prospective study. IRIS Study Group. Pediatr Infect Dis J 2000;19:592-7. 
38. Patrick SW, Burke JF, Biel TJ, et al. Risk of hospital readmission among infants with neonatal abstinence syndrome. Hosp Pediatr 2015;5:513-9.

39. Farhat R, Rajab M. Length of postnatal hospital stay in healthy newborns and re-hospitalization following early discharge. $N A m \mathrm{~J}$ Med Sci 2011;3:146-51.

40. Paul IM, Lehman EB, Hollenbeak CS, et al. Preventable newborn readmissions since passage of the Newborns' and Mothers' Health Protection Act. Pediatrics 2006;118:2349-58.

41. Mackie AS, Gauvreau K, Newburger JW, et al. Risk factors for readmission after neonatal cardiac surgery. Ann Thorac Surg 2004:78:1972-8.

42. Escobar GJ, Gonzales VM, Armstrong MA, et al. Rehospitalization for neonatal dehydration: a nested case-control study. Arch Pediatr Adolesc Med 2002;156:155-61.

43. Sword WA, Watt S, Krueger PD, et al. Understanding newborn infant readmission: findings of the Ontario Mother and Infant Survey. Can J Public Health 2001;92:196-200.

44. Martens PJ, Derksen S, Gupta S. Predictors of hospital readmission of Manitoba newborns within six weeks postbirth discharge: a population-based study. Pediatrics 2004;114:708-13.

45. Al-Omran A, Al-Abdi S, Al-Salam Z. Readmission for neonatal hyperbilirubinemia in an area with a high prevalence of glucose6-phosphate dehydrogenase deficiency: a hospital-based retrospective study. J Neonatal Perinatal Med 2017:10:181-9.

46. Anderson JG, Rogers EE, Baer RJ, et al. Racial and ethnic disparities in preterm infant mortality and severe morbidity: a population-based study. Neonatology 2018;113:44-54.

47. Aykanat Girgin B, Cimete G. Rehospitalization of preterm infants according to the discharge risk level. J Spec Pediatr Nurs 2017:22:e12165.

48. Boskabadi $\mathrm{H}$, Zakerihamidi M, Bagheri F. Frequency of major and minor risk factors associated with jaundice in hospitalized newborns. Tehran University Medical Journal 2017;75:141-51.

49. Breuer $\mathrm{O}$, Nasser $\mathrm{H}$, Natour $\mathrm{M}$, et al. Respiratory hospitalizations and rehospitalizations in infants born late preterm. Pediatr Allergy Immunol Pulmonol 2017;30:74-9.

50. Harron K, Gilbert R, Cromwell D, et al. Newborn length of stay and risk of readmission. Paediatr Perinat Epidemiol 2017;31:221-32.

51. Kuint J, Lerner-Geva L, Chodick G, et al. Rehospitalization through childhood and adolescence: association with neonatal morbidities in infants of very low birth weight. J Pediatr 2017;188:135-41.

52. Vohr B, McGowan E, Keszler L, et al. Impact of a transition home program on rehospitalization rates of preterm infants. $J$ Pediatr 2017;181:86-92.

53. McCormick J, Tubman R. Readmission with respiratory syncytial virus (RSV) infection among graduates from a neonatal intensive care unit. Pediatr Pulmonol 2002;34:262-6.

54. Fadum EA, Stanley B, Qin P, et al. Self-poisoning with medications in adolescents: a national register study of hospital admissions and readmissions. Gen Hosp Psychiatry 2014;36:709-15.

55. Tossone K, Jefferis E, Bhatta MP, et al. Risk factors for rehospitalization and inpatient care among pediatric psychiatric intake response center patients. Child Adolesc Psychiatry Ment Health 2014;8:27

56. Barker D, Jairam R, Rocca A, et al. Why do adolescents return to an acute psychiatric unit? Australas Psychiatry 2010;18:551-5.

57. Fite PJ, Stoppelbein L, Greening L. Predicting readmission to a child psychiatric inpatient unit: the impact of parenting styles. $J$ Child Fam Stud 2009;18:621-9.

58. Fite PJ, Stoppelbein L, Greening L, et al. Child internalizing and externalizing behavior as predictors of age at first admission and risk for repeat admission to a child inpatient facility. $A m J$ Orthopsychiatry 2008;78:63-9.

59. Steinhausen HC, Grigoroiu-Serbanescu M, Boyadjieva S, et al. Course and predictors of rehospitalization in adolescent anorexia nervosa in a multisite study. Int J Eat Disord 2008;41:29-36.

60. Blader JC. Symptom, family, and service predictors of children's psychiatric rehospitalization within one year of discharge. J Am Acad Child Adolesc Psychiatry 2004:43:440-51.

61. Castro J, Gila A, Puig J, et al. Predictors of rehospitalization after total weight recovery in adolescents with anorexia nervosa. Int J Eat Disord 2004;36:22-30.

62. Arnold EM, Goldston DB, Ruggiero A, et al. Rates and predictors of rehospitalization among formerly hospitalized adolescents. Psychiatr Serv 2003;54:994-8.

63. Enns MW, Cox BJ, Inayatulla M. Personality predictors of outcome for adolescents hospitalized for suicidal ideation. J Am Acad Child Adolesc Psychiatry 2003;42:720-7.

64. Lay B, Jennen-Steinmetz C, Reinhard I, et al. Characteristics of inpatient weight gain in adolescent anorexia nervosa: relation to speed of relapse and re-admission. European Eating Disorders Review 2002:10:22-40.

65. Pedersen J, Aarkrog T. A 10-year follow-up study of an adolescent psychiatric clientele and early predictors of readmission. Nord $J$ Psychiatry 2001;55:11-16.

66. Feng JY, Toomey SL, Zaslavsky AM, et al. Readmission after pediatric mental health admissions. Pediatrics 2017;140:e20171571-9.

67. McCarthy L, Pullen LM, Savage J, et al. Risk factors leading to increased rehospitalization rates among adolescents admitted to an acute care child and adolescent psychiatric hospital. J Child Adolesc Psychiatr Nurs 2017;30:105-11.

68. Auger KA, Davis MM. Pediatric weekend admission and increased unplanned readmission rates. J Hosp Med 2015;10:743-5.

69. Khan A, Nakamura MM, Zaslavsky AM, et al. Same-hospital readmission rates as a measure of pediatric quality of care. JAMA Pediatr 2015;169:905-12.

70. Tommey S, Peltz A, Loren S, et al. Potentially preventable 30day hospital readmissions at a children's hospital. Pediatrics 2016;138.

71. Minhas SV, Chow I, Feldman DS, et al. A predictive risk index for 30-day readmissions following surgical treatment of pediatric scoliosis. J Pediatr Orthop 2016;36:187-92.

72. Murray R, Logvinenko T, Roberson D. Frequency and cause of readmissions following pediatric otolaryngologic surgery. Laryngoscope 2016;126:199-204.

73. Roth JD, Keenan AC, Carroll AE, et al. Readmission characteristics of elective pediatric circumcisions using large-scale administrative data. J Pediatr Urol 2016;12:27.e1-27.e6.

74. Chern JJ, Bookland M, Tejedor-Sojo J, et al. Return to system within 30 days of discharge following pediatric shunt surgery. $J$ Neurosurg 2014;119:525-31.

75. Tahiri Y, Fischer JP, Wink JD, et al. Analysis of risk factors associated with 30 -day readmissions following pediatric plastic surgery: a review of 5376 procedures. Plast Reconstr Surg 2015;135:521-9.

76. McNamara ER, Kurtz MP, Schaeffer AJ, et al. 30-day morbidity after augmentation enterocystoplasty and appendicovesicostomy: a NSQIP pediatric analysis. J Pediatr Urol 2015;11:209.e1-209.e6.

77. Roxbury CR, Yang J, Salazar J, et al. Safety and postoperative adverse events in pediatric otologic surgery: analysis of American College of Surgeons NSQIP-P 30-Day outcomes. Otolaryngol Head Neck Surg 2015;152:790-5.

78. Vemulakonda VM, Wilcox DT, Crombleholme TM, et al. Factors associated with age at pyeloplasty in children with ureteropelvic junction obstruction. Pediatr Surg Int 2015;31:871-7.

79. Sarda S, Bookland M, Chu J, et al. Return to system within 30 days of discharge following pediatric non-shunt surgery. J Neurosurg Pediatr 2014;14:654-61.

80. Richards MK, Yanez D, Goldin AB, et al. Factors associated with 30-day unplanned pediatric surgical readmission. The American Journal of Surgery 2016;212:426-32.

81. Brown EG, Anderson JE, Burgess D, et al. Pediatric surgical readmissions: are they truly preventable? J Pediatr Surg 2017;52:161-5

82. Buicko JL, Parreco J, Abel SN, et al. Pediatric laparoscopic appendectomy, risk factors, and costs associated with nationwide readmissions. J Surg Res 2017;215:245-9.

83. Cairo SB, Raval MV, Browne M, et al. Association of same-day discharge with hospital readmission after appendectomy in pediatric patients. JAMA Surg 2017;152:1106-12.

84. Cairo SB, Ventro G, Meyers HA, et al. Influence of discharge timing and diagnosis on outcomes of pediatric laparoscopic cholecystectomy. Surgery 2017;162:1304-13.

85. Elias MD, Glatz AC, O'Connor MJ, et al. Prevalence and risk factors for pericardial effusions requiring readmission after pediatric cardiac surgery. Pediatr Cardiol 2017;38:484-94.

86. Polites SF, Potter DD, Glasgow AE, et al. Rates and risk factors of unplanned 30-day readmission following general and thoracic pediatric surgical procedures. J Pediatr Surg 2017:52:1239-44.

87. Roddy E, Diab M. Rates and risk factors associated with unplanned hospital readmission after fusion for pediatric spinal deformity. Spine J 2017:17:369-79.

88. Vedantam A, Pan IW, Staggers KA, et al. Thirty-day outcomes in pediatric epilepsy surgery. Childs Nerv Syst 2018;34.

89. Vo D, Zurakowski D, Faraoni D. Incidence and predictors of 30-day postoperative readmission in children. Paediatr Anaesth 2018;28:63-70.

90. Yu H, Mamey MR, Russell CJ. Factors associated with 30-day allcause hospital readmission after tracheotomy in pediatric patients. Int J Pediatr Otorhinolaryngol 2017;103:137-41. 
91. Attard TM, Miller M, Pant C, et al. Readmission after Gastrointestinal Bleeding in Children: A Retrospective Cohort Study. $J$ Pediatr 2017;184:106-13.

92. Braddock ME, Leutgeb V, Zhang L, et al. Factors influencing recurrent admissions among children with disabilities in a specialty children's hospital. J Pediatr Rehabil Med 2015;8:131-9.

93. Chave M, Marques-Vidal P. Factors associated with readmission of patients with congenital heart disease in a swiss university hospital. Pediatr Cardiol 2017;38:650-5.

94. Cohen JD, Morton RL, Eid NS. Hospital-associated risk factors with 30-day readmission of pediatric asthma patients. Pediatr Asthma Allergy Immunol 2000;14:211-7.

95. Frei-Jones MJ, Field JJ, DeBaun MR. Risk factors for hospital readmission within 30 days: a new quality measure for children with sickle cell disease. Pediatr Blood Cancer 2009;52:481-5.

96. Kun SS, Edwards JD, Ward SL, et al. Hospital readmissions for newly discharged pediatric home mechanical ventilation patients. Pediatr Pulmonol 2012;47:409-14.

97. Mackie AS, lonescu-Ittu R, Pilote L, et al. Hospital readmissions in children with congenital heart disease: a population-based study. Am Heart J 2008;155:577-84.

98. McNally T, Grigg J, Katie P. Hospital readmissions for preschool viral-wheeze. Paediatr Nurs 2005;17:15-18.

99. Nakamura MM, Zaslavsky AM, Toomey SL, et al. Pediatric readmissions after hospitalizations for lower respiratory infections. Pediatrics 2017;140:e20160938-9.

100. Neuman MI, Hall M, Gay JC, et al. Readmissions among children previously hospitalized with pneumonia. Pediatrics 2014;134:100-9.

101. Sacks JH, Kelleman M, McCracken C, et al. Pediatric cardiac readmissions: an opportunity for quality improvement? Congenit Heart Dis 2017;12:282-8.
102. Slone TL, Rai R, Ahmad N, et al. Risk factors for readmission after initial diagnosis in children with acute lymphoblastic leukemia. Pediatr Blood Cancer 2008;51:375-9.

103. Sobota A, Graham DA, Neufeld EJ, et al. Thirty-day readmission rates following hospitalization for pediatric sickle cell crisis at freestanding children's hospitals: risk factors and hospital variation. Pediatr Blood Cancer 2012;58:61-5.

104. Veeranki SP, Ohabughiro MU, Moran J, et al. National estimates of 30-day readmissions among children hospitalized for asthma in the United States. J Asthma 2018;55:695-704.

105. Vicendese D, Dharmage SC, Tang ML, et al. Bedroom air quality and vacuuming frequency are associated with repeat child asthma hospital admissions. J Asthma 2015;52:727-31.

106. Vicendese DA, Olenko A, Dharmage SC, et al. Modelling and predicting trends in childhood asthma hospital readmission over time. Allergy: European J of Allergy and Clin Immunology 2014;68:230.

107. Zhou H, Roberts $\mathrm{P}$, Dhaliwal S, et al. Transitioning adolescent and young adults with chronic disease and/or disabilities from paediatric to adult care services - an integrative review. J Clin Nurs 2016;25:3113-30.

108. Donzé J, Aujesky D, Williams D, et al. Potentially avoidable 30-day hospital readmissions in medical patients: derivation and validation of a prediction model. JAMA Intern Med 2013;173:632-8.

109. Shams I, Ajorlou S, Yang K. A predictive analytics approach to reducing 30-day avoidable readmissions among patients with heart failure, acute myocardial infarction, pneumonia, or COPD. Health Care Manag Sci 2015;18:19-34.

110. Hain PD, Gay JC, Berutti TW, et al. Preventability of early readmissions at a children's hospital. Pediatrics 2013:131:e171-81. 